\title{
Agents or Stewards? Contracting with Voluntary Organisations
}

\author{
Jo Cribb
}

\section{Introduction}

In order to escape a violent partner, take a disabled child swimming, get information about government services or extinguish a rural house fire, New Zealanders will generally interact with a voluntary organisation. In many areas of government voluntary organisations play an important delivery and operational role. A modest estimate (based on data from only 14 government departments) suggests that at least $\$ 650$ million of public social services are delivered each year by voluntary organisations via government contracts (Community and Voluntary Sector Working Party, 2001).

Agency theory was a foundational component in the design of New Zealand's state sector reforms in the 1980s and 90s. It has been strongly influential in shaping the contractually-based working relationship between government agencies as providers of funding for services and the community organisations that deliver those services on their behalf. Contracting between government agencies and voluntary organisations can, however, be fraught (Office of the Auditor General, 2003). Officials often find specifying what they wish to be delivered in the prescribed manner for contracts a challenge. Contract outputs risk becoming checklists for delivery and, as such, are not linked to the effectiveness of the service or outcome desired and create opportunities for 'creaming' the 'easiest' clients and tasks. From a voluntary sector perspective, small organisations often find the compliance costs of reporting onerous. As a result, newly-established voluntary organisations that provide services addressing emerging needs (such as those of refugee communities) can be excluded from funding and contracting processes.

This article, which derives from the author's doctoral research at Victoria University of Wellington's School of Government (Cribb, 2005), raises questions about the assumptions on which the current contracting system is based. It suggests that better outcomes may be achieved by a more discriminating application of agency theory in the design of contractual relationships between government agencies and community organisations, and by the application of an alternative model - one founded on stewardship theory.

\section{The agency basis of current contracting practice}

Voluntary organisations have existed in New Zealand since the beginning of colonisation. Scholars conclude that they have been dependent on state funding since the earliest years of organised government. Prior to the 1990s, the most common method of state funding for voluntary organisations was a system of grants and subsidies not usually attached to specific services. The early 1990s, a time of rising fiscal debt, saw a rethink of what was the appropriate size and function of the state. New Zealand's public management system, drawing on economic and administrative theories, was restructured (Boston et al., 1996). Several aspects of the restructuring altered how government agencies approached their relationship with voluntary organisations. In particular, based on insights from agency theory, the assumptions government agencies made about voluntary organisations changed.

For agency theorists, social and political life can be understood as a series of contracts. Principals delegate tasks, using contracts, to agents. Agents undertake work on principals' behalf in return for rewards. The focus of the theory is the contract governing the relationship between principal and agent and determining how the contract can be made as efficient as possible (Eisenhardt, 1989). Agency theorists interpret broadly what constitutes a contract. Contracts may be 'classical': arm'slength, formal and explicit. They may also be 'relational': implicit, open-ended, incomplete and based on obligations (Boston et al., 1996). 
Two problems can arise from contractual relationships: goal conflict, as the goals of the agents and their principals are usually different (Eisenhardt, 1989); and information asymmetry, as the agent often has more information than the principal about the task at hand. Under such conditions, it is difficult and expensive for the principal to verify what the agent is doing. The focus of agency theorists is on minimising the impact of these problems for the principal.

Agency theory, drawing on its neo-classical economic roots, assumes that individuals are 'rational, selfinterested utility maximisers'. As such, the interests of the principal and agent are bound to conflict because each party is assumed to be trying to maximise its personal benefits (Eisenhardt, 1989). Even if principals and agents have similar goals, assumptions about the nature of individuals leads to the conclusion that agents will shirk by producing outputs at a higher cost than required or producing outputs of a lower quality than specified. This is termed moral hazard: a lack of effort on the part of the agent. Agents may also claim that they have skills and capacity to deliver that they actually do not. Adverse selection may occur as principals contract with agents who have misrepresented their abilities (Eisenhardt, 1989).

Principals have a number of options available to them to minimise the risk of their agents shirking, cheating or operating with guile. They can provide incentives for the agent to operate according to the principal's wishes, monitor the agent's actions to ensure they are doing so, and sanction the agent if their performance is not satisfactory.

Agency theory was influential in the restructuring of a number of relationships within the public service. Purchase agreements between ministers and chief executives for the purchase of services from government departments were introduced, as were performance agreements between chief executives and the State Services Commissioner. The contract model was also applied to the relationship between government agencies and voluntary organisations. The Treasury was a powerhouse of the state sector restructuring. Briefings written towards the end of the restructuring period showed that Treasury officials were concerned about the quality of services delivered by voluntary organisations. Government, the papers concluded, needed to be vigilant about regulating and monitoring voluntary organisations' delivery to reduce information asymmetries and ensure they did not shirk. The development of contracting policies and practices was based on such assumptions (New Zealand Treasury, 1995).

Grant-based funding ceased for many voluntary organisations in the early 1990s and was replaced with contracts for the delivery of services. Government agencies attempted to specify what services they required, introduce monitoring regimes, and sanction poorly performing organisations by not renewing their contracts. Clear objectives in contracts were designed to ensure voluntary organisation providers focused on results. Reporting on the objectives would provide good information to government agencies about the provider and the quality of the service (Boston et al., 1996).

Overlaying the introduction of contracting was the pressure to reduce government spending. Competition between providers was encouraged. Voluntary organisations were often required to tender. Market pressures were sought to ensure efficiency of service delivery. A drive to increase transparency and accountability was also an important aspect of the restructuring. Accountability was interpreted as answerability and took the form of formal reporting against specified measures (Mulgan, 2003). Enhanced accountability was seen as a way of developing more efficient and effective organisations and service delivery.

By the mid-1990s, voluntary organisations with a funding relationship with government had become service providers. Many had a formal, 'classical' contract with government. What they were required to provide, in what quantity, at what quality and price - all this was specified in the contract.

\section{Voluntary organisations' experience of contracting}

The great majority of voluntary sector managers and board members surveyed in my doctoral research, which focused on four community organisations of differing types, focused their attention on their relationships with their clients. They felt they were most accountable to their clients for the quality of the services they provided. They generally identified their relationship with government as a hindrance. Contracting and funding agreements with government agencies were seen to be driving down standards of care. Poorly designed 
programmes, irrelevant performance measures and a piecemeal approach to service provision were seen to detract from the quality of service they could provide to their clients.

Respondents' perceptions of how they were viewed and treated by government officials were uniform. They felt that officials treated them as 'poor cousins'. They perceived that their skills were not recognised, their ideas and suggestions not valued and their concerns not considered valid. And they perceived that they were being treated as agents, while, on the other hand, officials were operating as if they were principals

More specifically, respondents perceived that:

* They were viewed as inferior, while officials saw themselves as experts. There was no negotiation or dialogue about the contents of the contract or funding agreement. (Agency theory assumes that the principal has a superior position in regard to the agent and will work to maintain the power imbalance. Indeed, principals enact mechanisms to control agents - such as financial incentives and monitoring regimes - and ensure power asymmetries.)

* Officials did not trust them. They expected the respondents to try to defraud the system or produce poor quality work. The integrity and expertise of respondents was not recognised. (One of the key tenets of agency theory is the assumption that agents have different interests from those of the principal and will seek to better themselves at the principal's expense.)

* The main form of communication between respondents and officials was monitoring reports. The relationship was distant and paper-based. (Agency theory promotes external monitoring as a mechanism to control age

* Reporting focused on specific outputs that were often irrelevant to service quality or organisational performance. (Detailed pre-specification of contracts is another tool agency theorists promote to control agents.)

* Contracting was an economic tool used to try to maximise efficiency. Respondents perceived that officials took a 'take it or leave it' approach focused on competition between providers to drive down the price of service delivery.

\section{Are the assumptions of agency theory valid?}

At its core, agency theory predicts that agents will have different aims from their government funders (the principals), that they will operate opportunistically and with guile to achieve their own aims, and that they will shirk as much as possible. In this research it was found, however, that respondents had similar high-level goals to officials. Officials and respondents both aimed to achieve positive outcomes for recipients of their services. Respondents saw that their primary accountability obligation was to their clients, and they perceived themselves to be going the 'extra mile' at their own expense to fulfil it. They saw themselves working for clients in the face of barriers created by the contracting process. Rather than shirking by attempting to provide less service than required, as agency theory predicted they would do, respondents were actively fund-raising to increase levels of service provision, independently of the funding provided by government officials.

International studies have drawn similar conclusions. For example, Rasmussen et al.'s 2003 study found that government officials and voluntary sector managers shared a client focus. Indeed, agency theorists have similarly come to accept that the assumption of goal conflict may not always be valid. Eisenhardt (1989) concedes that goal alignment may occur in highly socialised or clan-orientated firms, or in situations where self-interest gives way to selfless behaviour. As goal conflict decreases, so does the need for in-depth monitoring. Agents will behave in a manner acceptable to the principal regardless of the level of monitoring.

\section{Agents or stewards?}

It may be timely to consider an alternative approach. Stewardship theory takes as its starting point the assumption of goal alignment, and is increasingly seen as an important framework for structuring relationships (Block, 1996).

The origins of the concept of stewardship are biblical. Stewards, as valued employees who are entrusted with running households, are mentioned in both the Old and New Testaments. Stewards were seen as servants of someone or something greater than themselves, were committed to their work, and had the discretion to take risks on behalf of their masters. 
Proponents of stewardship theory argue that proorganisational and collective behaviours are of higher utility than the individualistic, self-serving behaviours assumed by agency theory (Dicke and Ott, 2002). Put simply, if the organisation does well, its members will do well, so they invest their energy in their organisation's success (Davis et al., 1997). People will thus put the organisation's needs first. They are not assumed to want to shirk or act opportunistically, as agency theory has it. Instead, they are motivated to work to achieve the organisation's goals (Block, 1996).

Stewards, like others, have basic survival needs, such as a regular salary. The differences between a self-interested agent and a steward are in how these survival needs are met. Stewards realise that there is a trade-off between personal and organisational needs, and choose to work for organisational needs. By doing so, stewards assume their personal needs will be met (Davis et al., 1997). Some theorists acknowledge that stewards may work for altruistic reasons - unselfish concern and devotion to others - without expected return. Dicke and Ott (2000) argue that altruistic motives best explain voluntary organisations and their employees, as employees are selected and socialised to care about and serve clients.

Less controlling organisation structures and mechanisms are needed for stewards. Extending the autonomy of stewards maximises the benefits of their behaviour. Informal and intrinsic accountability mechanisms, rather than 'hard' legalistic or mechanistic ones, are best suited to stewards: the promulgation of professional standards, peer review, and mechanisms that build a sense of internal responsibility (Dicke and Ott, 2000). Control can be counter-productive because it signals that the steward is not trusted with a level of discretion. Such control will lower the motivation of a steward to work for the organisation (Davis et al., 1997).

If a stewardship approach were to be adopted to guide the government-voluntary sector contracting relationship, a number of changes would occur. Stewardship theorists would see current accountability mechanisms, such as monitoring, audit and reporting, as superficial. They would instead focus on ensuring that goals are shared. This would mean government agencies would take the time to understand what the voluntary organisations were trying to achieve, how they were doing it and where there was a congruence of goals.
When it had been identified that goals were shared, the contracting process could begin. There would be a large investment of time at the beginning of any relationship.

If, after discussions with a voluntary organisation, it were clear that the organisation had different goals from those the officials were trying to achieve (or that it was not capable of delivering what was required), officials would seek another provider. In practice, this might mean that organisations currently contracting with government would not be offered future contracts: a potentially difficult and politically volatile situation.

Once a relationship had been established, voluntary organisations would be trusted to get on with the job. Performance measures focusing on measuring outcomes for clients would be jointly developed over time. Blanket controls and 'boilerplate' contracts would not be used. Non-financial motivations would be acknowledged. Knowledge generated from the performance measures would be used to modify service delivery. Dialogue between parties would focus on delivery problems, and potential improvements or innovations. The information asymmetries that are problematic in principal-agent relationships would still exist: the staff of voluntary organisations have more information about service delivery than officials. Under a stewardship framework, such asymmetries would not be seen as a potential source of risk for principals (such as an avenue for inflating contract prices), but rather such knowledge would be seen as expertise that should be incorporated into policy processes.

The additional time made available to officials by the reduction of detailed monitoring of contracts could be used by them to provide long-term strategic guidance, and research on effective service delivery and the attainment of outcomes. The stewards (voluntary organisations) would be freed from detailed reporting and the provision of government-designed piecemeal programmes to do what they do best - that is, deliver in-depth services to clients. The principals (officials) could support this through research, development and investment in strategy.

Officials could choose to contract better with fewer organisations, given the resource-intensive nature of establishing relationships. This would not be without risk for the voluntary sector. Fewer organisations might receive funding. A trusted 'inner circle' could develop. Under such circumstances, new organisations might be 
excluded. Organisations receiving funding could also find it difficult to maintain their unique qualities as they developed a close relationship with government, as predicted by neo-institutionalists (DiMaggio and Powell, 1983).

Of benefit to the voluntary sector, however, would be the increased investment government agencies could make in building the capacity of voluntary organisations. In particular, officials might seek to improve the ability of voluntary organisations to monitor how well they are doing in fulfilling their mission, so that they could self-regulate. Evidence indicates that these organisations have little capacity to monitor closely their own performance.

A number of conditions would need to be met if stewardship theory were to effectively govern the government-voluntary sector relationship. Voluntary organisations would need sophisticated systems of performance management and self-criticism to ensure that they were working towards the shared goals. This author's research and other studies have found that internal performance measurement is a weakness, and that the level of self-regulation needed to ensure that such organisations are working to enhance the public good is not present.

Both parties need to be interested in each other and looking for better ways to serve the public (that is, to have an effective focus on outcomes). The author found that most respondents believed that officials had little interest in them and that the contracting process was mainly about delivering outputs for clients rather than outcomes.

Government needs to recognise that it puts up cultural barriers to working with voluntary organisations. The report of the Community and Voluntary Sector Working Party (2001) provided specific examples of such barriers operating in the New Zealand context. These included the speed at which policy makers expect the voluntary sector to respond to draft documents. A number of organisations reported that they were unable to participate in policy processes in a meaningful way. Umbrella organisations, which seek feedback from their constituencies before engaging with government agencies, saw themselves particularly hampered by the short timeframes allowed. The speed and demands of the political cycle provide one example of a cultural barrier for voluntary organisations that prioritise discussion and consensus.
Moreover, government agencies need to be prepared to share decision making. For the Community and Voluntary Sector Working Party, this meant providing genuine opportunities for organisations to comment on policy and involvement in the early stages of policy development. Respondents' perceptions of the contracting process as a 'take it or leave it' one suggest that this is still a long way off.

Time is also needed to develop shared expectations and sensible performance measures. Experimentation will be needed. However, as demonstrated by the example of a contract in the recent Auditor General's report on the government contracting processes, practices currently do not result in shared expectations:

There was no 'meeting of minds' on the part of the Ministry and [the voluntary organisation it contracted with] as to the length and expected outcomes of the contract. The parties were confused over the length of the contract and the expected outcomes during the term of the contract. (Office of the Auditor General, 2003, p.59)

\section{The way forward?}

In theory, adopting a stewardship rather than an agencytheory frame may address many of the limitations of the current contracting regime. However, the reality is much more complex.

Stewardship theory is untested, particularly in voluntary sector research, and the enthusiasm with which some of its proponents advocate this approach makes their claims seem too good to be true. As Arthurs and Busentiz (2003, p.155) argue, 'stewardship theory paints an excessively rosy picture of the steward'.

Government agencies need to make voluntary organisations accountable for taxpayers' money. They need to be seen to be in control (Dicke, 2002). As guardians of the public purse, public agencies take what can be considered a risk-averse approach. The mechanisms of external control, such as monitoring and reporting, can be seen to provide the needed assurance to both ministers and the public that taxpayers' money is being used effectively (Davis et al., 1997). Being accountable for taxpayers' dollars is one example of the different set of pressures that officials as opposed to voluntary organisations operate under. 
Another pressure originates from the three-year political cycle and the associated changes in policy and programmes. Such change will make it difficult for officials to establish committed long-term relationships with voluntary organisations. A regime built on the assumption that providers should be allowed a high level of discretion is unlikely to be feasible in this context. Public accountability systems can be seen as a trade-off between discretion and assumed innovation and efficiency, on one hand, and the need for control on the other. Increased control comes at an increased cost: the resources needed to monitor behaviour, as well as reduced levels of innovation and the performance improvements that can result from such innovation.

At the heart of the debate is the issue of how much discretion agencies can allow their providers: how far can they trust them? Finding the balance between control and trust is the key question for any alliance, and there are no easy and obvious answers. Both come at a cost to the organisations involved. For a relationship based on trust to develop, government agencies and voluntary organisations will need to become familiar with each other. Trusting relationships are only formed between actors who have established close bonds. The interests of the parties must be aligned. As previous discussions of agency theory have shown, when each party is selfinterested and working towards different goals, control becomes a central feature of the relationship, at the expense of, or as a substitute for, trust (de Leon, 2003). For trust to develop in a relationship a sense of shared higher-level purpose is needed. Trust is also most likely to eventuate when parties have taken care and time in choosing their partners.

However, in trusting voluntary organisations, government agencies will be implicitly accepting the risks associated with being dependent on them for the delivery of services. Trust implicitly involves loosening mechanisms of control, and relying on voluntary organisations to deliver services of an acceptable quality. Such interdependence increases the vulnerability of government agencies (particularly to poor performance by voluntary organisations) and increases the potential for betrayal or harm from voluntary organisations (such as the potential for being defrauded). Understandably, such risk is not readily acceptable to either public sector managers or politicians.
In sum, stewardship theory is based on assumptions that may portray more accurately than does agency theory the government-voluntary sector contracting experience. But it is certainly not to be regarded as any sort of panacea, and if it were to be applied as slavishly as agency theory was in the late 1980s and early 90s, it too would give rise to all sorts of unintended, and often undesirable, consequences. The least that can be said is that, given the importance of the contracting relationship for the delivery of public services, there needs to be much more exploration of the validity of the assumptions upon which government agencies and voluntary organisations enter into contractual relationships.

\section{References}

Arthurs, J. and L. Busentiz (2003) 'The boundaries and limitations of agency theory and stewardship theory in the venture capitalist/entrepreneur relationship', Entrepreneurship: Theory and Practice, Winter, pp.145-62.

Block, P. (1996) Stewardship: choosing service over selfinterest, San Francisco: Berrett-Koehler Publishers Inc.

Boston, J., J. Martin, J. Pallot and P. Walsh (1996) Public Management: the New Zealand model, Auckland: Oxford University Press.

Community and Voluntary Sector Working Party (2001) Communities and Government: potential for partnership: whakatopu whakaaro, Wellington: Ministry of Social Policy.

Cribb, J (2005) 'The Accountability of Voluntary Organisations: implications for government funders', $\mathrm{PhD}$ thesis, School of Government, Victoria University of Wellington.

Davis, J., D. Schoorman and L. Donaldson (1997) 'Toward a stewardship theory of management', Academy of Management Review, 22, pp.20-47.

de Leon, L. (2003) 'On acting responsibly in a disorderly world: individual ethics and administrative responsibility', in B.G. Peters and J. Pierre (eds), Handbook of Public Administration, London: Sage.

Dicke, L. (2002) 'Ensuring accountability in human services contracting: can stewardship theory fit the bill?', American Review of Public Administration, 4.

Dicke, L. and J.S. Ott (2002) 'A test: can stewardship theory serve as a second conceptual foundation for accountability methods in contracted human services?', 
International Journal of Public Administration, 25, pp.463-87.

DiMaggio, P. and W. Powell (1983) 'The iron cage revisited: institutional isomorphism and collective rationality in organisation fields', American Sociological Review, 48, pp.147-60.

Eisenhardt, K. (1989) 'Agency theory: an assessment and review', Academy of Management Review, 14, pp.57-74

Mulgan, R. (2003) Holding Power to Account: accountability in modern democracies, New York: Palgrave MacMillian.

New Zealand Treasury (1995) 'The Voluntary Sector in New Zealand', unpublished papers released under the Official Information Act, Wellington.

Office of the Auditor General (2003) Inquiry into Public Funding of Organisations Associated with Donna Awatere Huata MP, Wellington.

Ott, J.S. and L. Dicke (2000) 'Important but largely unanswered questions about accountability in contracted human service', International Journal of Organisation Theory and Behaviour, 3, pp.283-317.

Rasmussen, K, D. Mallroy and J. Agarwal (2003) 'The ethical climate of government and non-profit organisations', Public Management Review, 5, pp.83-97.

Jo Cribb recently completed her PhD at the School of Government, Victoria University of Wellington, and has worked in various capacities in the New Zealand Public Service. She can be contacted at jo@cribbwaterman.net 